\title{
The social construction of dementia: Systematic review and metacognitive model of enculturation.
}

Alessandro Bosco ${ }^{1}$, Justine Schneider ${ }^{2}$, Donna Maria Coleston-Shields ${ }^{1}$, Paul Higgs $^{3}$, Martin Orrell ${ }^{1}$

Affiliation: ${ }^{1}$ Division of Psychiatry and Applied Psychology, School of Medicine, University of Nottingham, Nottingham, United Kingdom; ${ }^{2}$ School of Sociology and Social Policy, University of Nottingham, Nottingham, United Kingdom; ${ }^{3}$ Division of Psychiatry, Faculty of Brain Sciences, University College London, London.

Corresponding author: Alessandro Bosco, Room A10, Institute of Mental Health, Innovation Park, University of Nottingham, Triumph Road, Nottingham NG7 2TU, United Kingdom. Email:

Alessandro.bosco@nottingham.ac.uk Phone: (+44) 7453512212.

Research sponsor: This work was supported by the Economic and Social Research Council [grant number ES/J500100/1] 


\begin{abstract}
Background. Stigma in dementia may be influenced by how the condition has been socially constructed through history.

Objectives. To conduct a systematic review tracing the historical representations of dementia, through the perspective of cultural transmission theory and social constructivism.

Methods. A systematic search was run on five electronic databases: Wellcome library, PsycINFO, CINAHL, IBSS, and EMBASE. Articles were screened and analysed through deductive content analysis. We further applied a communication system theory to graphically describe how dementia has been experienced through time.

Results. Ten primary sources and 33 secondary sources were consulted. Seven themes emerged from the analysis: A problem of aging, use it or lose it, divine punishment, loss of agency, psychosis and insanity, brain degeneration and objectification, and dementia as a social condition. Each theme corresponds to a particular way of conceptualising dementia and influencing the modern representations of the condition.
\end{abstract}

Conclusion. Past characterisations of dementia have influenced modern views around the condition. It is through enculturation that these views are interpreted, assimilated, or rejected by individuals and transmitted within and across cultures. A better understanding of the social construction of dementia, can improve public health approaches to rehabilitation and care.

Words: $213 / 250$

Keywords: Dementia, social construction, communication network, history. 
Dementia is a neurodegenerative syndrome affecting over 47 million individuals worldwide and damaging the individuals' cognition, social functioning, and their ability to engage in everyday tasks [1]. The condition has also an impact on the life of all the agents involved in the process of care (e.g. family, friends) at the physical, psychosocial, and economic levels [1].

The way individuals perceive of dementia has been influenced by socio-cultural and political contexts throughout history and holds different meanings across cultures [2]. Moreover, the social context influences the way individuals have experienced dementia through history also relating to the way the condition is socially constructed in modern societies [3].

The socio and cultural climate of specific historical periods, or 'Zeitgeist', has fostered various perceptions around dementia within society. Previous historical reviews on the concepts of dementia have described how people living with the condition in certain time periods were socially condemned as sinners [4], or deserving of a divine punishment due to past sins before the manifestation of symptoms [5], or were sometimes institutionalised because retained unfit to exercise their basic human rights as citizens [6].

However, cultural transmission theory suggests that these beliefs are learned through social interaction and they are not only specific of their time, but also transmitted through time [7]. Unlike the experiential learning process, cultural transmission does not require active participation, as knowledge is passively acquired by simply living in a certain societal milieu [8]. This is explained in terms of enculturation, a process through which some beliefs to be shared between generations and consequently through time [8]. For example, person-centred care in 1980s sparked from the previous disability rights movement in the USA in the 1970s, which acted against the medicalisation of mental health disorders, in favour of a more socially-accepted interpretation of non-communicable conditions. In turn, the protest in the 1970s against the medical model, was fuelled by previous sociocultural and political contexts that privileged exclusively the neuropsychiatric examination of mental health disorders [9].

Previous historical analyses of the concepts of dementia have focussed largely on the clinical symptoms and pathology, these were mainly time-bound. Empirical work has been done into the current imagery of dementia intended as conundrum [10], in which the scientific effort to find a cure of the condition does not match with the call for improved quality of care, or pointing at the strong association between negative views on dementia and the poor quality of care received [11]. However, no in-depth historical study of the social constructs of dementia at the societal level has been conducted and no analysis has taken into account the process of enculturation for the forming of modern belief(s) around dementia. This review explores changes in societal concepts of dementia reflecting historical milestones, with the aim of improving the understanding of modern social representations of the condition. We aimed to accomplish this by conducting a systematic review tracing the historical representations of dementia, through the perspective of cultural transmission theory and social constructivism.

\section{Methods}

As the scope of our investigation is broad and concerns the history of a health condition, we opted for a systematic review to explore the topic, and undertook deep analysis of the texts identified, in order to map possible key elements, with reference to different points in history. Two theoretical frameworks were used to guide the enquiry and analysis:

- Cultural transmission theory. Health conditions have historical cultural bases and the concepts are 'socially distributed, culturally administered and culturally functional' [12]. We 
therefore looked for historical accounts in documents, by retrieving information on the social policies and social conditions. These may be expected to influence the social construction of dementia, as well as to be influenced by it.

- Social constructivism. According to social constructivism, reality is not a given, nor defined a priori, but rather it is transformed and shaped by socially-interacting individuals. Applied to the experience of dementia, individuals enact their condition and experience it by developing a meaning for it, which is socially and culturally bound through time and place. We used social constructivism to organise the findings, along with interpreting and synthesising the results of our searches.

Since the relevant literature is not quantitative, we followed the standards of good practice in qualitative research set by Guba [13] (i.e. credibility, transferability, dependability and confirmability). By doing so, we aimed to reach adequate levels of validity in our findings [14]. We also triangulated the information we retrieved against other sources (i.e. secondary historical sources that reported different historical versions compared to those reported in the studies that we included in the review), according to the principle of 'confirming/disconfirming' $[15,16]$.

\section{Data collection}

We used purposive searching for the retrieval of empirical studies and historical documents. This approach enables us to consider each study identified as a case and to select only those providing the information most relevant for our enquiry, which could be synthesised for the review $[15,16]$. For this purpose, we followed the principle of 'intensity' (i.e. how rich and accurate is the information the studies provide), and 'relevance' (i.e. how socio-politically relevant is the information the studies provide) $[15,16]$.

The search included five databases: Wellcome Library (History of Medicine collection and medical archives), PsycINFO, CINAHL, IBSS (The International Bibliography of the Social Sciences), and EMBASE. In consultation with an expert librarian at the University of Nottingham, we used the following search domains to define our search strategy:

- Dementia: dement*, alzheimer*.

- History: Histor*

These terms were adapted for each of the databases.

\section{Eligibility criteria}

The document is:

a) About dementia with or without comorbid physical or mental health diagnosis.

b) A primary historical source (i.e. document reporting raw data of events) or secondary historical source (i.e. document analysing primary documents).

c) A report on the history of dementia, with a primary focus on:

- How the concept of dementia has developed through the years.

- How the condition was experienced by societies.

- Historical milestones at a societal level.

- The socio-cultural debate around the condition and any dementia-relevant reforms.

d) In English or has been translated into English.

e) A contemporaneous or retrospective account concerning dementia. The former may confer a deep knowledge of the political conditions impinging on societal shared beliefs and values at 
a certain period in time. The latter may be examined against important historical changes such as political and social movements through time.

We also engaged in a broader search and considered alternative historical reproductions (e.g. artistic photos, novels, poems), such as the work by Thane [17] on 'The Long History of Old Age', when these helped factor in how either dementia or aging was depicted at the time, as both terms have often been associated through history.

\section{Identification of primary sources and quality appraisal of secondary sources.}

To maximise the retrieval of primary sources, other than retrieving primary sources through electronic databases, we further extended our search to include grey literature, by considering the first 100 hits on Google scholar. We also consulted the 'NU-search' library catalogue of the University of Nottingham to retrieve relevant information on textbook and hardcopies. All the sources selected for review were cross-referenced.

We described primary sources around 1) the main argument presented, 2) how the argument challenges (if applicable) the contemporary values and beliefs, and 3) and the aims of the authors (Table 1). We did not formally evaluate primary sources. Also, the research team included translations of primary documents and considered these primary sources through agreement.

In regard to the quality appraisal, the first author $(\mathrm{AB})$ developed a screening tool adapted from the Critical Appraisal Skills Programme (CASP) checklist [18] to evaluate the secondary sources (Table 2). This checklist enabled us to conduct a systematic assessment of the methodology used for data collection and analysis, and to explore the clarity and quality of reporting of the study objectives, findings and contribution to knowledge in each case. Documents were not excluded on the grounds of clarity, nor for decreased quality in their reporting.

\section{Data analysis}

Deductive content analysis [19] was used to investigate the historical processes underlying the societal experience of dementia and the way it has been socially constructed through history. Content analysis proves effective in categorising data from socially defined phenomena, and for creating a conceptual map of those events that influenced the determining of these phenomena [19], as it is the case of our investigation of dementia and its usage in history. The main elements of non-material culture by Matsumoto [20] around aging and dementia (i.e. social norms, ideas, beliefs, values, and shared symbols) informed the synthesis of the findings. It is to be acknowledged that culture is both a social construct and an individual construct [21], for this reason, as much as our analysis was made in reference to existing sources, we used our own 'culture' to interpret our findings (i.e. Western European culture).

In order to reach rigour and robustness in our findings, we undertook the three phases of preparation, organising and reporting as described by Elo and Kynga [19]. Specifically, (AB) created a structured matrix for categories that enabled the coding of data according to each pre-defined category. In order to avoid losing important concepts, the research team did not discard data that did not fit with the categories, but rather, we considered them as new categories, in case they added new information. The process of data extraction and organisation was facilitated by the use of NVivo 11 [22].

During our analysis we found that the influence of authoritative figures of the time was key in persuading societies to adopt specific beliefs around dementia. We therefore felt that it was appropriate to utilise a paradigm that could explain how the message is transmitted within the society and how authoritative figures influence or maintain a belief at the societal level. 
For this reason, the analysis was informed by the systems theory paradigm [23] to describe the process of forming a collecting understanding of dementia through communication occurring in specific periods in history: how authorities at the time influenced the shaping of the concept, the way the message was conveyed to persuade the person (and society at large) to adhere to the belief, and the role of the general population in the transmission of the message. From the evidence gathered, it was evident that the transmission of the belief/message around dementia was not a one-way process, but rather included feedback that the decoder of the message (receiver) would send back to the encoder (those influencing the transmission of the belief) within a social cultural context and in a specific time in history. We therefore also used an interaction model of communication theory to explain what promoted the enculturation around specific views on dementia in modern times [24].

\section{Results}

The systematic search was conducted on $15^{\text {th }}$ October 2017. Out of 25,452 documents retrieved (EMBASE: 15827; PsycINFO: 4894; Wellcome Library: 3138; CINAHL: 46; IBBS: 1547), 43 were included in the analysis (33 secondary sources and 10 primary sources) (Figure 1 for study flow chart).

The quality appraisal was conducted only on 33 secondary sources as we found it not feasible to use quality screening tools on primary documents as there was no systematic reporting of methods nor of paradigm used. Documents were found to be of high quality in the way they clearly reported the use of multiple sources for interpretation. However, we found it difficult to attribute scores for items 3 and 4 .

Content analysis. Seven themes were identified, each emerging in different periods in history.

\section{A problem of aging.}

Early remarks on dementia trace back to classical times, when the condition was associated with aging rather than illness [25]. Old age was depicted as a period in life in which most human decay occurs and much of this decay is responsible for the mental regression affecting aging individuals. The five life stages model attributed to Pythagoras (570-495 BC) in the $7^{\text {th }}$ century B.C., is one of the earliest representations of how life was understood at the time. According to Pythagoras, age 63 and 81 constituted the 'senium' period of life, when cognitive and mental decline were inevitable $[26,27]$. The senium may also be regarded as one of the earliest portrayals of dementia, as Pythagoras contended that old age was the period when "The scene of mortal existence closes... and ... the system returns to the imbecility of the first epoch of the infancy" [26,28].

This association of aging with dementia led to the social construction of the condition as a natural life manifestation and arguably also to stigmatising societal views around the process of aging. Such negative social construction around old age and decreased judgment was also reflected in different spheres of society, including the legal system [29]. Court judge Solon (638-558 BC) in 500 B.C. amended the inheritance laws and legislated that inheritance could be passed on to 'extra-family' heirs, only if they were not affected by decreased judgment caused by old age [29,30]. The association of aging with mental failure was also addressed by Hippocrates, who used "paranoia"/imbecility to describe the mental decline in old age (ca. 460-377 B.C.) and later by Plato (424-423 BC) and Aristotle (384-322 B.C.) [5, 29].

Galen (129-200 AD) provided the term 'morosis' to define dementia [29,31,32]. The term 'morosis' described a condition in which 'the knowledge of letters and other arts are totally obliterated' and where the affected individuals find it difficult to retrieve easy information from their memory, 
including their names [29]. Given the existing societal views associating inevitable deteriorating cognitive abilities with aging [6], Galen's views prevailed, and dementia continued to be considered a condition of old people, who were often referred to as demented or cognitively and mentally impaired.

This association with mental failure has also been reported in other periods in history. William Shakespeare [33] describes the seven ages of man, with the last characterised by 'second childishness and mere oblivion, Sans teeth, sans eyes, sans taste, sans everything'. These negative connotations of aging, cognitive and mental failure still permeate in modern times:

"I was one of them, dreaming of a perfect and healthy old age...Now, at fifty-eight, I realize the foolishness of my dreams as I watch my brain self-destruct from Alzheimer's." [34]

A more realist representation of ageing is provided by Alice Munro's 'Winter Wind' [35], where the character of a nursing home resident is characterised by unrecognizable memories of the past, and whose life is devoid of positive emotions for the future. In 'Picture of the Ice' [36], her character Austin tries to mask his signs of ageing to avoid discrimination. This portrayal of old age reflects the expectations posed by the Western culture on ageing found in the early and middle $20^{\text {th }}$ Century celebrating youth [37].

\section{Use it or lose it.}

In contrast to the Greek philosophers, the Roman poet Cicero (106-43 BC) contended that the causes for 'senile debility' were not to be found in the aging process, but rather in a passive way of living life - a life devoid of active engagement and proactive thinking [38]. In the essay 'Cato Maior de Senectute', Cicero argued that, through engaging in active life, a person could fight off disease and mental regression [38]. The concept of successful aging in terms of active participation in life resonates in modern times to similar extents. For example, in Vietnamese culture there is a 'use it or lose it' approach to life, according to which dementia takes over if no active life is maintained [39]. Research evidence similarly points at the role of active training for the preservation of mental functioning in older people as a way to prevent the onset of dementia symptoms [40]. The role of neural stimulation in increasing the density of neocortical synapses seem to be key in favouring the preservation of healthy brains $[41,42,43,44]$. Several studies seem to point at this association, with authors reporting education as one protecting factor against the forming of pathological brain structures that could lead to dementia, such as amyloid load [45], or neuritic plaques in the grey matter of the brain $[46,47]$.

However, in classical period, this theory was overpowered by the concept of dementia as an inevitable condition, irrespective of any individual mechanisms that could be acted out to fight off the mental deterioration and which reflects the strong influence of Aristotle over classical Roman thinking $[17,29]$.

\section{Divine punishment.}

During the early Middle Ages dementia was considered to be a consequence of original sin, an external force limiting free will $[48,49]$. This led to the association of dementia with divine punishment. Theological doctrines permeated much of the cultural belief of the time, but a first sign of change was when Roger Bacon (1214-1294) argued that the understanding of complex phenomena required empirical (i.e. scientific) observation [49]. Victimised for his views by religious authorities, Bacon was imprisoned on accusation of witcheraft $[49,50,51]$. 
The religious dogma exacerbated the stigma associated with aging and favoured the construction of both aging and dementia in terms of divine punishment [29,52]. Consequently, in 1400-1500, in Western European countries, many individuals with cognitive impairment (and dementia in many cases) were trialled, as they were retained not worthy of the glory of God. The court sentences inflicted to them were deemed essential to prevent that their sins could 'infect' the 'pure of spirit'. Similarly, anyone acting against this doctrine was banished [5,53].

Religion has represented a channel for the transmission of the meaning around dementia. In modern times, Christianity, holds unclear views, or perhaps simply differing interpretations on whether dementia is a consequence of sinful acts practised by the individual before the diagnosis, a deserved condition of all human beings for they are descendants of Adam's race, or still, for some Puritans, a form of sin linked to insanity and to which all humans are destined to [54]. Although the religious interpretations of the Bible are what fuels the transmission of the message, compared to the past, the sociology of religion points at the role of the organisation within doctrines and their use of the social media for the forming of modern constructions of dementia [54]. The mediatisation of religion, the use of social media to promote religious values, is responsible for the modern characterisations of the condition, with some messages still promoting the association between human action and divine punishment, by contending, for example, that 'blogging sometimes leads to dementia, doesn't it?' (Reported by the Cardinal Marx, leader of the German bishop conference in 2015) [54,55].

Christianity has not been the only doctrine favouring the spread of such meaning around dementia. According to Sikhism, each member of the community has to respect the principle of 'seva' and support the congregation through selfless acts (e.g. caring for the sick, helping the poor) 'with the exception if you have dementia, then you have to repent your sins' [p.279] [56]. This brings stigmatising views on dementia not only to the person living with the condition, but also to the rest of the family. Similarly to Christianity and other monotheistic religions, disciples of Sikhism learn that mental and physical conditions need to be cared for within the family or the congregation. Dementia becomes then a family matter whose sin of the person with the condition is shared by the whole family [56]. Still in some African countries (e.g. Nigeria) the behavioural psychological symptoms of dementia are considered signs of evil possessions affecting those with weakened spirits (i.e. sinners) [57]. Such collective construction of dementia in terms of sinful act and divine punishment inevitably leads to stigmatising views around the condition with consequences of social withdrawal and exclusion for the person living in the community and the family. From the words of a residential facility nurse in South Africa:

"When persons act in strange ways the talk starts in villages and townships: they say 'that one has been bewitched'... they go to these old people, vandalise their houses, burn their houses... they accuse them of being witches" (p. e172;) [58].

Delayed engagement with health and care services is a consequence of such association nonetheless [59]. Similarly, for some traditional members of the Macedonian community, dementia is considered a punishment for past sinful acts, or a curse for exhibiting inappropriate behaviours that are condemned by the community. Receiving a diagnosis of dementia becomes associated with selfexclusion from social activities. Members of the community who are not directly related to the person with dementia, may even withdraw from participating to community events if either the person with the condition or his/her family members continue to attend [39]. 


\section{Loss of agency.}

Following the period of scientific development called the Enlightenment, during which the dominance of religious authority was challenged, the religious belief linking dementia to divine sin was less prevalent, although there was still confusion around the condition and several speculations were made around terminology [25,29]. Terms such as 'lethargie' (Cosin, 1592) [60], 'stupidity' [61], and 'insensitivity' (Battie, 1758) [60], were used to describe the condition [62]. These terms denoted a negative characterisation of dementia, viewed as decreased sensitivity acquired with age. For Willis (1621-1675) in his London Practice of Physick [61], the ageing person becomes 'by degree dull'. A key correlate of this process seems to be that the person affected also loses entitlement to practice agency because of his/her decreased intellectual capacity [29]. Even at the end of the $18^{\text {th }}$ century, the classification of mental conditions produced by Cullen (1710-1790) in 1776, reported 'Amentia Senilis' as a neurosis, characterised by the decay of cognitive and mental functioning $[5,63]$.

A growing sense of what we might call individual responsibility can be seen, in Western Europe, as an effect of the Reformation with the dissolution of the monasteries having a big impact on the issue of caritas, shifting the responsibility from the church to the civil society. The implementation of the poor law spread across Europe as eligibility criteria for relief became widespread instead of 'works of grace'. Such societal responsibility was further prompted by the Enlightenment ideas on communitarian support. This is reflected in writings about the unshaken collective responsibility of care' towards old people experiencing failing physical and mental capacities [5]. Generally, the provision of care was seen as a tripartite responsibility: the old person (who had to retain agency until loss of capacity), the family (having a duty of care), and the community (providing support where all else failed, through charities, for example) $[29,64]$. Social upheavals such as the agrarian revolution, and the beginnings of industrialisation, with mass migration to towns, separated aged parents from their traditional carers and so communities had to come up with substitutes. Workhouses where indigent people were given very basic shelter in return for labour became the last resort for people of all ages with cognitive impairment [65]. Despite a change has been made in the living conditions of people with dementia, and independent forms of living have replaced shelters, the frailty of people with the condition may still be experienced as a lack of capacity to reason.

\section{Psychosis and insanity.}

In the $19^{\text {th }}$ century, a gradual differentiation between senile dementia and other forms of dementias emerged more prominently [66]. Esquirol (1772-1840) introduced the importance of conducting a systematic clinical observation to identify subcategories of mental disorders $[29,67]$ and differentiated dementia (a cognitive decline and mental impairment consequent on acquired disease) from amentia (decreased intellectual functioning acquired before birth or at the early stages of human development). However, old people with dementia still experienced institutionalisation for their condition, and a labelling of insanity was still applied to this group of patients [68].

The construction of dementia in terms of insanity was maintained because of the similarities that the condition shared with psychosis in regard to lethargic behaviour. Hence, patients who were detached from reality 'psychotic', but whose behavioural symptoms were not active enough to confirm a diagnosis of mania, were classified as having dementia $[4,68]$. The association with psychosis reinforced the assumption that people with dementia had psychotic behavioural alterations, and therefore lunatic asylums were regarded as optimal care settings for both populations [69]. The 
association with psychoses also led to Kraepelin's (1856-1926) definition of schizophrenia as 'dementia praecox' in 1891 and to differentiating dementia occurring in old age as 'senile dementia', caused by a loss of cognitive functioning $[69,70,71]$. Towards the end of the $19^{\text {th }}$ century, empirical observation was regarded as the gold standard for the ascertainment of different aetiologies of dementia (e.g. vascular and senile) and for the study of the epidemiological relevance of senile dementia in aging individuals, compared to other mental health conditions [29].

Still today, the association with insanity remains in some artistic representations and work of literature. According to Foucault [72], some of the clinical manifestations of dementia are found in conditions that Thomas Willis defined as 'stupiditas, sive morosis' in the De Anima Brutorum (p.235) [61]. The concept of stupidity or 'unreason' [72] has permeated in modern times. It is not surprising then, that the work by Theodore Gericault in 'The Portrait of The Insane' [73], influenced the photographs by Nicholas Nixon on people with dementia, in which the artist captures their elusive gazes in moments of unawareness [74]. Although the mouth of the subjects is open they do not communicate words and their empty gaze transmits no meaning. The audience is left with no imagination on what the person with dementia may think or say.

There is still stigma around dementia in modern societies. For example, In Arabic culture, dementia is translated in 'kharaf' and most commonly used to indicate that a person has 'lost her/is mind' [39]. The fear of becoming victims of prejudice for carrying a diagnosis, leads people with dementia to hide their symptoms and their family members to limit their visits to their loved ones with the condition [39].

\section{Brain degeneration and objectification.}

Societal views of dementia were still anchored in the association of the condition with psychosis, hence in the concept of 'insanity', but efforts were made by $19^{\text {th }}$ Century scholars to conduct systematic ('pathological') examinations of the condition, investigating brain atrophy and vascular degeneration post mortem [75,76].

In the early $20^{\text {th }}$ century, in both Europe and the United States, mental health disorders and cognitive impairments came to be explained through a brain disease discourse that belonged to the medical profession (e.g. Alzheimer, 1906) [77]. Neurology and psychiatry vied for ownership of clusters of symptoms, which, grouped into different mental health conditions, led to the conceptualisation disorders as unique entities. This was reflected on dementia as well, which was classified as organic brain syndrome in the Diagnostic and Statistical Manual of Mental Disorders (DSM-1) in 1952, and later acquired the criteria for dementia and Alzheimer's disease (DSM-III-R, DSM-IV and DSM-IVTR) $[78,79]$. Dementia was more and more conceived of as an organic disorder. From here dementia was conceived as a 'neuro-psychiatric' condition [80].

The emphasis on the process of scientific diagnosis and the categorisation of symptoms into diseases or disorders tended to result in the objectification of patients, who were often reduced to their symptoms or diagnosis, regardless of other human characteristics This objectification of the person as a mere 'host' of a degenerative disease prevailed throughout the first half of the $20^{\text {th }}$ Century. However, this reductionist approach proved increasingly unsatisfactory as an explanation of the clinical symptoms of dementia. The medicalisation of dementia tended to make health services responsible for its care. Consequently, there was a containment strategy as part of the state provision in which patients who could not be rehabilitated, as in the case of people with advanced dementia, 
tended to live out their remaining years in a hospital or poor law infirmaries, often at the expense of the state. Where state provision was not forthcoming, families provided nursing care. Medicalisation of dementia still permeates the care pathway in dementia, from the time of diagnosis, when medical categories are used to discriminate between disorders to the care package containing difficult medical terms and given to people living with the condition for the treatment of symptoms. This medical approach to dementia is still responsible for experience of decreased dignity and consequent objectification in people with dementia [81].

\section{Dementia as a social condition.}

Late $20^{\text {th }}$ century critiques such as the anti-psychiatry movement challenged the medical model of mental illness [82], and pointed to the influence of social factors over mental disease. The notion of institutionalisation was formed [83] and the tendency for formal care settings such as long-term hospitals to deprive people of their self-determination was recognised [84]. Economic forces converged with social movements to reduce the provision of long-term hospital care for people with dementia as well as people with other diagnoses. This led to an increase in the provision of community care (e.g. in nursing homes) and a rapid decline in the numbers of psychiatric beds within the National Health Service (NHS) [85]. This trend was favoured by the uncapped DHSS (Department of health and Social Security) board and lodgings payment budget, with nursing homes taking advantage of this source of income. The effect was having a disproportionate number of people diagnosed with dementia [86].

Kitwood's theory suggesting that neurological impairment could be exacerbated by malignant social psychology helped to foster the development of a new framework of care that could replace the 'old culture of dementia care' [87]. This was a new social construction of dementia that emerged from challenging the 'standard paradigm' of the medical model and was underpinned in the concept of positive care relationship: through positive care practice, the personhood of the people with dementia can be promoted [87]. It followed that the person with dementia was placed at the centre of the care 'conversation'. People with dementia were to be considered persons rather than 'patients' or 'simply rational individuals'. Person-centred care, also known as patient centred care, client-centred care, or resident-centred care [88], came to be regarded as the gold standard for care $[9,89]$ and inspired other models of care based on positive care relationships (i.e. relationship care model as in the senses framework) [88].

In recent decades, the presentation of dementia in the media has often been more respectful, better reflecting the views and needs of people with dementia. This has favoured the increase of dementia awareness at the societal level through literature and arts, for example. Photography is one of the artistic productions that catered much of the attention on dementia. Artists started to use this modern medium to capture the eyes and ageing bodies of people with dementia through an intersubjective stance that could promote a sense of empathy in the audience. Through the work series 'portraits of dementia sufferers', Jeff Bowering constructs a realist meaning around the faces of his models, a meaning that humanises them and paralyses the audience through the use of dramatic representation of people with dementia: their gaze is human, and different from a vegetative state typical of past characterisations of the condition $[90,91]$.

Similarly, on a policy level, there started to be legal acknowledgements for people with dementia. Much of the influence was brought by the UPIAS's (Union of the Physically Impaired Against Segregation) views around the social barriers experienced by people with physical difficulties [92]. Steps forward were made with The Human Rights Act (1998), with the inclusion of dementia in the 
Equality Act (2010), and through the United Nations Convention on the Rights of Persons with Disabilities (2006) to protect people with dementia (among others) against stigma and discrimination. This coupled to the discourse around 'successful aging', has pushed new boundaries to the entitlements of people with dementia and their role in society. People with dementia are becoming active citizens, able to influence positive views around dementia through network communication, advocacy programmes and charity campaigns.

\section{Discussion}

This article synthesises and conveys the socio-cultural processes underpinning the construction of dementia across a broad period of human history to help explain how certain socio-cultural meanings developed around the concept of dementia, and how these evolved.

Cultural transmission theory in dementia. By interpreting our findings through cultural transmission theory, we found that specific meanings resonated through history and shaped the way we conceive of the condition today. This is to say that the way dementia is experienced in modern times is a product of past constructions of the condition and that different meanings are not time-bound. For example, the association of dementia with divine punishment that was maintained in the middle ages, is still today practised in some religious groups and explained in terms of God's wrath [93], karmic punishment for past sinful acts [94] or witchcraft possession [95]. As reported in our review, there are multiple views around dementia that are present in contemporary societies. It is through enculturation that these views are transmitted and maintained in accordance with the values and beliefs shared by different cultures. The meanings around dementia are interpreted, assimilated, or rejected by individuals in their socio-cultural context [96]. Hence, meanings are negotiated by individuals based on their social location (e.g. gender, social class) their biography [96,97], but also according to the level of self-awareness [98]. As poor self-awareness may lead to decreased levels of assertion towards their role in society and promote or maintain negative connotations around dementia. In addition, the forming of these meanings is influenced by the presence of other social constructions, such as the social representation of aging [99].

These views when negative (e.g. when they are associated with stupidity, divine punishment, insanity) can generate stigma and have negative consequences for the person with dementia and their family, but also for agents directly involved in the delivery of dementia care (e.g. health care professionals) and for society at large $[100,101]$.

Enculturation around the concepts of dementia in modern times. In this review, the interaction model of communication describes the forming of the collective understanding of dementia, how the meaning around the condition has formed and has been transmitted in modern society. Although, it holds true that meanings are transmitted through generation, in the last two decades, globallynetworked communication capability has spurred a new form of public opinion, with a change in the distribution of power to influence ideology and beliefs. This has promoted a more participatory democratic citizenship, where the actors (i.e. citizens) have a channel to share their views with the larger community (i.e. the rest of the population) for good or ill (i.e. in presence of positive or negative meanings around dementia) [102]. It is to be acknowledged, that network communication is also used by the authorities (e.g. to promote political campaign, reinforce maintained beliefs) with the aim to persuade and control the masses. What has changed from the past, however, is the growing interdependence of each member of the society and the authorities, hence translated into our model, between the authority (e.g. policy makers) and the person with dementia (Figure 2 for an illustration of the model of enculturation). 
As illustrated in this model, the message around dementia is not passively experienced by the person with the condition, as s/he applies an interpretation to the concepts by means of her/is own understanding of dementia. Through self-awareness, the person may assert her/is own identity and influence at societal level a more positive construction of the condition. In case of negative connotations of dementia (e.g. mainly focused on the fact that dementia is a non-curable condition) and in presence of poor levels of self-awareness, the person is unable to actively influence positive imaginary of dementia. Consequently, negative meanings around the condition may be spread across and within societies. When there are no opportunities at societal level promoting positive views around dementia, there is risk to create barriers in institutional and community practises for social equity and cultural diversity (e.g. barriers impeding the creation of dementia friendly community). These barriers may lead to what Thomas and Milligan [92] defines as psycho-emotional disablism, a term describing all those negative behaviours that are unintentionally or intentionally acted out by the large community of people without dementia towards people with the condition. Psycho-emotional disablism can act as a vicious cycle and affect the personal dimension of the individual with dementia and have an impact on her/is self-esteem and decisional power, hence proving limiting for her/is social action. However, positive levels of self-awareness can help the person to practice self-assertion in presence of these social barriers.

Such process of democratisation of dementia, may occur through social capital, when the organisation of the society promotes the active involvement of people with dementia and their carers in the sociopolitical life of the community. In contrast with the horizontal view of knowledge distribution [103], we feel that active participation should be across systems, actively informing the development of social policies across all different sectors of the societies (e.g. health and social care, housing). These social policies may be promoted by the modern accessibility of information, through online discussion forums for example (i.e. Alzheimer's Society). These online platforms (e.g. Facebook, Twitter) both positively and negatively impact the perception and stigma around dementia in contemporary societies.

\section{Strengths and limitations}

A strength of this paper is the systematic methodology used for the retrieval of articles. This follows the PRISMA checklist [104]. The scope is broad, since we used five databases with quite diverse specialisms, ranging from the social sciences, psychology, to more specific databases within the biomedical domain, and history-specific domain as in the case of the Wellcome Library. This strategy enabled us to retrieve major works relevant to the objectives of our investigation, but it also gave us the ability to screen a large number of documents that would not be possible otherwise.

The principles of confirming/disconfirming to triangulate the information reported in the studies was selected for the analysis with other secondary sources when these reported differing historical versions of the events. In addition, the research team met multiple times to refine the search strategy, to agree on the methodology to use for data extraction and to engage in the quality of data reporting. A librarian based at the University of Nottingham was consulted for the search strategy and to determine which checklist to use to assess the quality of the documents retrieved.

In regard to the limitations, these lay mainly in the use of the CASP checklist, which was more limited in determining the quality of primary and secondary historical documents. It is important to acknowledge though, that this was out of our control as the current systems for the quality appraisal of historical documents only target authenticity (i.e. type of paper utilised, material used for printing) and conservation of these resources (i.e. how to conserve the document through time, the existence of proof such as receipt for its conservation). However we developed a checklist adapted from the CASP 
that could prove effective in the appraisal of historical reviews. Another limitation relates to the very exploration of the social construction of dementia, as this requires the analysis of different forms of documents e.g. letters, artefacts, we were only able to consider the documents listed in the databases we consulted.

Also, it is to be acknowledged that this inquiry was mainly based on western-centred societies and although we were able to retrieve some examples of eastern cultures, these were mainly reported in documents whose authors were from western countries. A quite large period of human history has not been covered chronologically as we were interested in social meanings around the condition rather than a chronological description of the history around dementia.

\section{Conclusion}

Through history dementia has commonly been associated with ageing and decline. In recent decades as life expectancy and years of active life has increased, the notion of 'successful ageing' has been incorporated into the discourse around dementia. While such consideration of people with dementia promotes positive views around the condition, and may favour their equal consideration as active agents able to operate in society, it does require the establishment of a dementia-friendly society that can accommodate the needs of this population and to avoid that people living with dementia may feel overwhelmed by the attempt to fulfil these expectations [105]. In addition, there is the risk that people with dementia may prefer to be socially excluded rather than engaging in a society designed for the young and able-bodied. A discourse around co-production, explained as a communal effort 'to find a shared solution', may prove effective in acknowledging the need for support of people living with dementia and at the same time empowering them [106]. Work still needs to be undertaken to bring the rights of people with dementia on an equal positioning with the rest of the population. For this purpose, new models of care aim to set benchmarks of good care through the active involvement of people with dementia in co-producing their own care pathway.

\section{Acknowledgments}

Professor Tom Dening at the University of Nottingham contributed with precious comments on the manuscript. 
Figure 1. Flow chart for selection of papers.

\section{Identification}

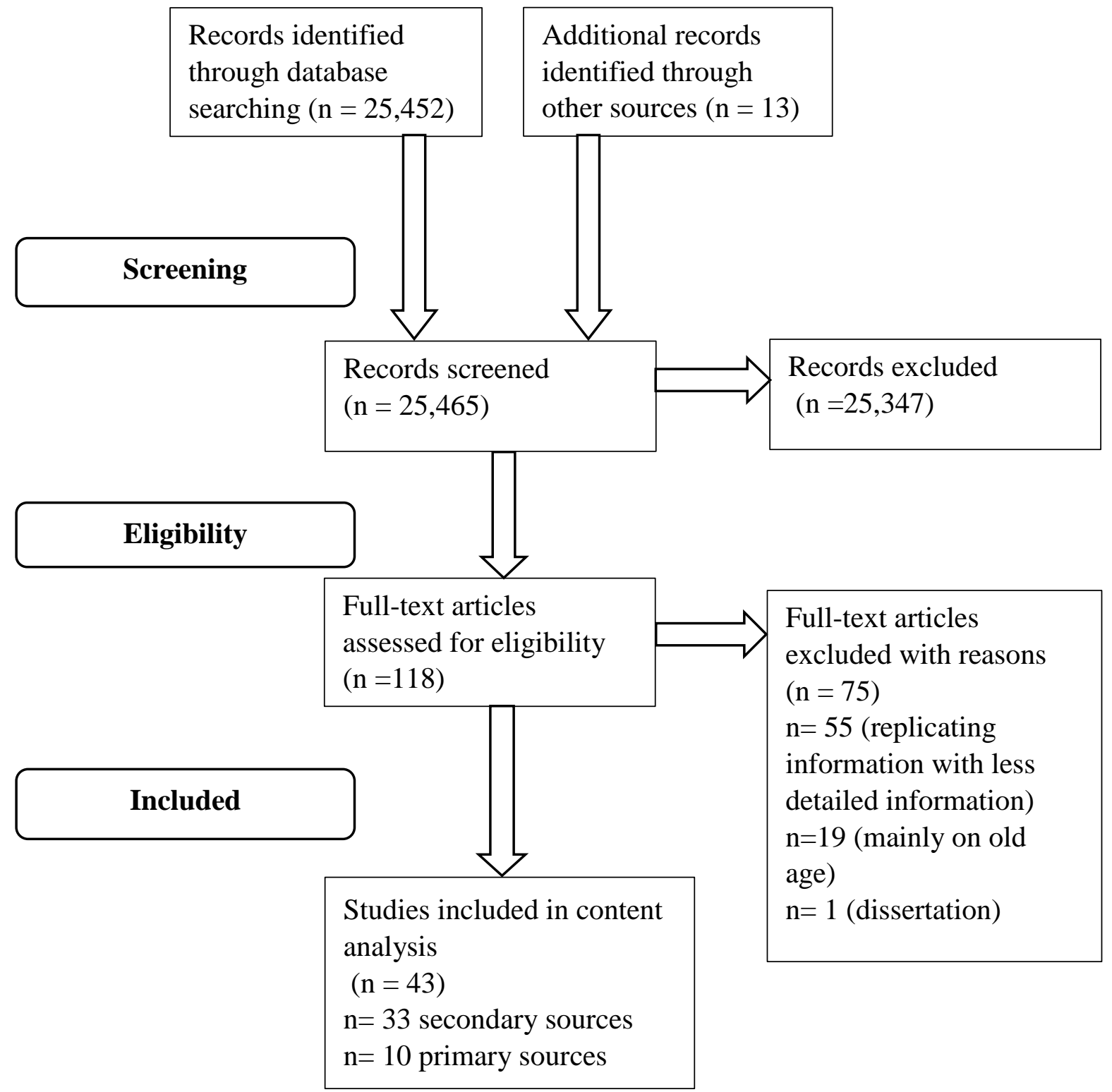


Table 1. Description of primary sources $(n=11)$.

\begin{tabular}{|c|c|c|c|}
\hline \multicolumn{4}{|c|}{ Primary sources } \\
\hline Historical era & Author & Primary documents & Description \\
\hline \multirow[t]{4}{*}{$\begin{array}{l}\text { Classical } \\
\text { Antiquity }\end{array}$} & $\begin{array}{l}\text { Solon } \\
\text { (translated and } \\
\text { commented } \\
\text { by Rhodes \& Leao, } \\
\text { 2016) }\end{array}$ & $\begin{array}{l}\text { The Laws of Solon: A New } \\
\text { Edition with Introduction, } \\
\text { Translation and Commentary }\end{array}$ & $\begin{array}{l}\text { The authors report translated versions of Solon's writings into English with } \\
\text { added commentaries on Attic society. } \\
\text { Both authors have extensive expertise on Athenian law-making institutions. } \\
\text { Rhodes has extensively produced work on Athenian politics (e.g. The } \\
\text { Athenian Boule -Oxford, 1972) and on Aristotelian society (e.g. Athenaion } \\
\text { Politeia - Oxford, 1981). Leao has produced work on Plutarch. It caters to an } \\
\text { educated audience. Dementia was associated with altered states of judgement } \\
\text { and awareness. }\end{array}$ \\
\hline & Cicero & Cato Maior de Senectute & $\begin{array}{l}\text { 'On old age' is Cicero's treatise on aging and death. The narrative takes the } \\
\text { form of a dialogue. We find the main character Cato who engages almost in a } \\
\text { monologue throughout the work. We further find typical characteristics of } \\
\text { aging in the character whose wordy and confusing speech recalls the } \\
\text { inevitable cognitive decline posed by old age. However, Cicero maintains also } \\
\text { a positive view of old age in that he contends that old people who remain alive } \\
\text { after a certain age are to be considered strong and fit to practise their will. It } \\
\text { caters to an educated audience. }\end{array}$ \\
\hline & Celsus & De Medicina & $\begin{array}{l}\text { Celsus's work De Medicine remains one of the few sections of a larger } \\
\text { encyclopaedia still available and it is regarded as a treatise of Alexandrian } \\
\text { medicine. The work is divided in } 8 \text { books around diet and exercise, causes of } \\
\text { disorders, and treatments. The language used in the text is complex and it } \\
\text { carers to a professional audience. Celsus provided one of the first } \\
\text { differentiation of dementia from delirium defined as phrenesis. Dementia was } \\
\text { considered a more deteriorating condition that manifested after delirium. }\end{array}$ \\
\hline & $\begin{array}{l}\text { Galen (translated into } \\
\text { English } \\
\text { By Johnston, 2006) }\end{array}$ & $\begin{array}{l}\text { Galen: On Diseases and } \\
\text { Symptoms }\end{array}$ & $\begin{array}{l}\text { Galen's work on the classification of disorders provide a bridge between the } \\
\text { theoretical foundations and clinical practice. The language used is moderate in } \\
\text { tone which reflects the dogmatic views on medicine of the time. It caters to an } \\
\text { educated audience. Galen defined dementia as morosis and linked the } \\
\text { condition to a process of ageing. }\end{array}$ \\
\hline
\end{tabular}




\begin{tabular}{|c|c|c|c|}
\hline Modern History & Willis & Practice of Physick & $\begin{array}{l}\text { Willis uses a terminology based on negative connotation of old age to } \\
\text { characterise cases of what at the time dementia symptoms may have been at } \\
\text { the time (morosis, stupidity). It caters to a medical audience. }\end{array}$ \\
\hline \multirow{4}{*}{$\begin{array}{l}\text { Late modern } \\
\text { history }\end{array}$} & Cullen & $\begin{array}{l}\text { First lines in the practice of } \\
\text { physic }\end{array}$ & $\begin{array}{l}\text { In his work, Cullen described dementia as amentia and as a subclass of } \\
\text { disorders affecting judgement. One type of amentia was linked to memory } \\
\text { problems and defined amentia Senilis, which was regarded as a condition } \\
\text { consequent to ageing. Cullen's work mainly caters to a medical audience. } \\
\text { Dementia was considered a failure of mental and cognitive functioning. }\end{array}$ \\
\hline & Esquirol & $\begin{array}{l}\text { Des passions considérées } \\
\text { comme causes, symptômes, et } \\
\text { moyens curatifs de l'aliénation } \\
\text { mentale }\end{array}$ & $\begin{array}{l}\text { Esquirol's medical thesis was greatly influenced by the work of Pinel. In his } \\
\text { work, Esquirol reported case studies and maintained the firm idea on the } \\
\text { association of psychological and somatic disorders and the highly } \\
\text { interconnection of thoughts and feelings. In his case studies, the author } \\
\text { reported the use of restrictive and punitive therapeutic courses in asylums as } \\
\text { opposed to the use of alternative treatment for mental disturbances. It caters to } \\
\text { a medical audience. Dementia was considered a consequence of acquired } \\
\text { disease. }\end{array}$ \\
\hline & Wilks & $\begin{array}{l}\text { Clinical notes on atrophy of } \\
\text { the brain }\end{array}$ & $\begin{array}{l}\text { In his work, Wilks attributed the abnormal changes of brain atrophy to senile } \\
\text { dementia. He further reported a modern description of the brain hemispheres. } \\
\text { It mainly caters to medical audience. Wilks proposed one of the first } \\
\text { classification of dementia as organic brain syndrome. }\end{array}$ \\
\hline & Alzheimer & $\begin{array}{l}\text { Uber eine eigenartige } \\
\text { Erkrankung der Hirnrinde } \\
\text { (Translated by Hurley \& } \\
\text { Wells, 1999) }\end{array}$ & $\begin{array}{l}\text { Alzheimer's case work contains clinical observations of aggressive form of } \\
\text { dementia with an early onset. In order to maintain the original contents of the } \\
\text { author's work, the English translation has not respected some of the English } \\
\text { grammar conventions, and the structure of the sentence has been reported as } \\
\text { used in the original language. It caters to a medical audience. }\end{array}$ \\
\hline $\begin{array}{l}\text { Post-Modern } \\
\text { Movement }\end{array}$ & Kitwood & Dementia reconsidered & $\begin{array}{l}\text { Kitwood's work opened the stage to a public debate on dementia by critically } \\
\text { discussing the inadequacy of the medical model in exampling the } \\
\text { psychosocial symptoms of the condition and the role of the social } \\
\text { environment in shaping such experience. Kitwood employs a dialogue form in } \\
\text { the text, whose content is referenced by previous research and professional } \\
\text { experience. It mainly caters to social care professionals, however the language } \\
\text { used is made accessible to a larger audience with no previous expertise on } \\
\text { dementia. }\end{array}$ \\
\hline
\end{tabular}


Table 2. Appraisal checklist for reviews on historical documents.

\begin{tabular}{|c|c|c|c|}
\hline Checklist & & & \\
\hline Screening questions & Yes & Can't tell & No \\
\hline $\begin{array}{l}\text { 1. Did the review address a clearly focused question? } \\
\text { Hint: Problems may be in the following: } \\
-\quad \text { The years covered in the article. } \\
-\quad \text { The historical processes. }\end{array}$ & & & \\
\hline $\begin{array}{l}\text { 2. Did the authors look for the right type of documents? } \\
\text { Hint: 'The studies should } \\
-\quad \text { Be relevant to the scope of the study. } \\
-\quad \text { Be a primary source (or consult different secondary sources to } \\
\text { compare and contrast the validity and accuracy of the } \\
\text { information reported. }\end{array}$ & & & \\
\hline
\end{tabular}

Detailed Questions*

3. Do you think you considered all the relevant documents?

Hint: Search for

- Databases consulted.

- Follow up from reference lists.

- Personal contact with experts.

- Search for unpublished as well as published studies.

- Search for non-English language studies.

4. Did the review's authors do enough to assess the quality of the included studies?

Hint: Did the authors assess the quality of the information from other sources.

5. If there was differing information from other sources, did the authors reported this in the review?

Hint: Look for

- The information was similar from study to study.

- The reasons for any variations in the information reported are discussed.

6. Did the authors favoured the use of primary sources?

Hint: See if

- $\quad$ The document reports the current contextual factors.

- The document report first-hand account.

7. Does the review clearly discuss the findings in reference to the context within which it is situated?

Hint: Look for

- Implication for policy, practice.

- Historical determinants influencing current socio-political decisions.

8. Can the findings be applied to the local context?

Hint: The social context covered by the review could be sufficiently different to your social context to cause concern.

9. Do the authors report if the findings apply to other social contexts?

Hint: If the authors reported their findings to be generalizable to an international context, and how if they did.

10. Were all important outcomes considered?

Hint: Do you think the authors would have required more information?

Items 1, 2, 3, 4, 5, and 10 were adapted from the CASP checklist.

* Items 3 to 10 are applicable only if items 1 and 2 have received a positive response. 
Figure 2. The social construction of dementia: a metacognitive model of enculturation.

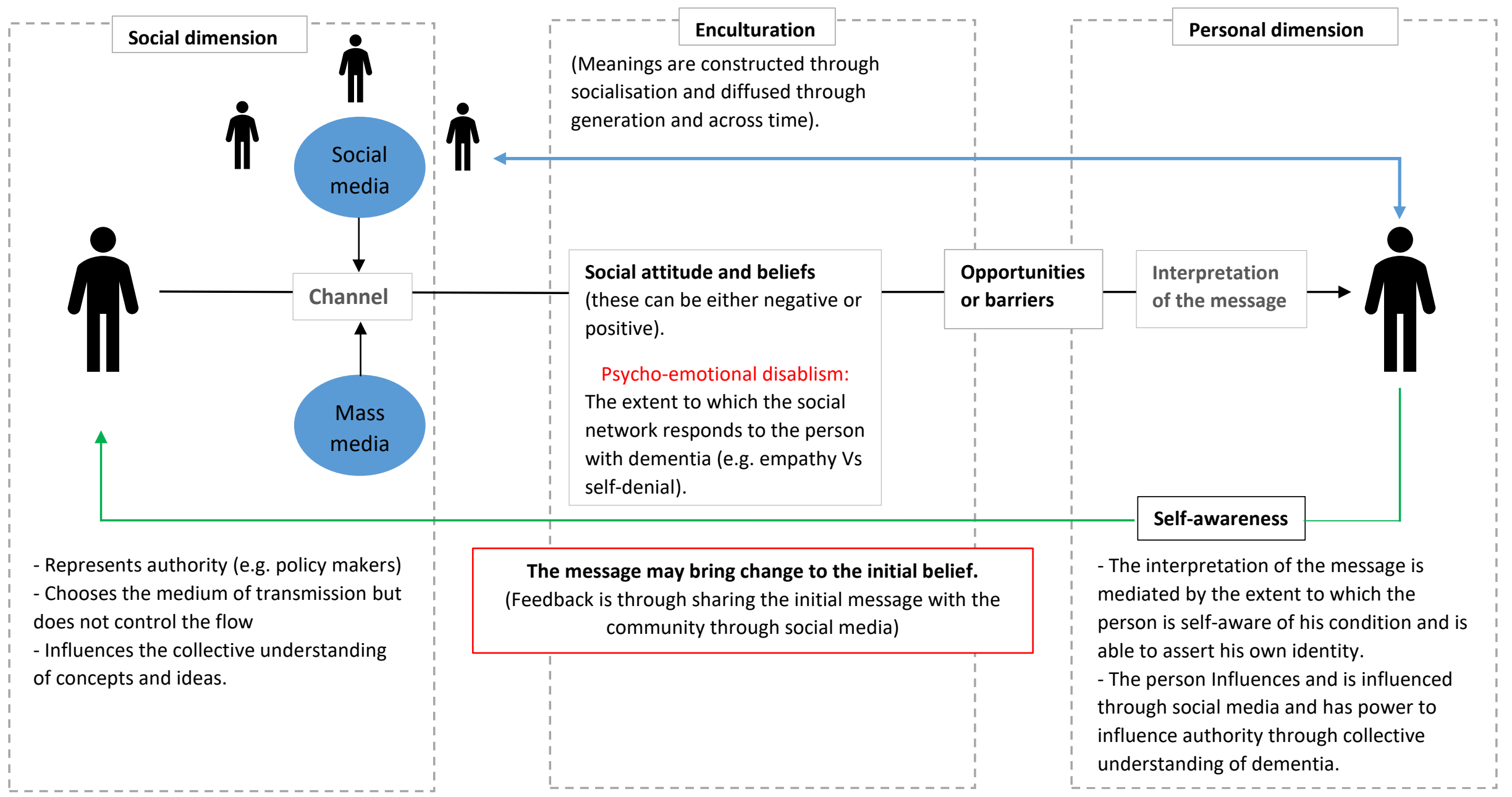

Technological advances in social networking has given rise to a new form of power organisation, in which societal beliefs are now dispersed across societies. Unlike the past, the person with dementia now has more freedom to influence the collective understanding of concepts and beliefs on a global scale. The level of selfawareness of the person with dementia helps regulate their ability to assert their identity, which in turn mediates their interpretation of the message around dementia. 


\section{References}

[1] World Health Organisation (WHO), Global Action Plan on the public health response to dementia 2017-2015. http://apps.who.int/iris/bitstream/handle/10665/259615/9789241513487eng.pdf;jsessionid=F8822EDFC51F2544A66F76F5C235AA2C? sequence=1, 2017 (accessed 23 September 2018)

[2] M. Kane, Ethnoculturally-sensitive practice and Alzheimer's disease, American Journal of Alzheimer's Disease. 15(2) (2002) 80-84.

[3] M. Shadlen, E.B. Larson, Unique Features of Alzheimer's Disease in Ethnic Minority Populations. Full-Color Aging, Gerontological Society of America, Washington, DC, 1999.

[4] G.E. Berrios, R. Porter, (1995). A history of clinical psychiatry - the origin and history of psychiatric disorders, Athlone, London, 2009, pp. 34-71.

[5] H. Feldman, Atlas of Alzheimer's disease, CRC Press, 2007.

[6] F. Boller, M.M. Forbes, History of dementia and dementia in history: An overview, Journal of the Neurological Sciences. 158 (1998) 125-133.

[7] L.L. Cavalli-Sforza, M.W. Feldman, K.H. Chen, S.M. Dornbusch, Theory and observation in cultural transmission. Science. 218 (1982) 19-27.

[8] J.E. Grusec, P.D. Hastings, P. D. (Eds.), Handbook of socialization: Theory and research, Guilford Publications, 2014.

[9] Mental Health Foundation (UK), Dementia, rights, and the social model of disability. https://www.mentalhealth.org.uk/sites/default/files/dementia-rights-policy-discussion.pdf, 2015 (accessed 13 August 2018)

[10] M. Lock, The Alzheimer Conundrum: Entanglements of Dementia and Aging, Princeton University Press, Princeton, New Jersey and Woodstock, UK, 2013, 328.

[11] L.R. Beard, Living with Alzheimer's: Managing Memory Loss, Identity, and Illness, NYU Press, Paperback, 2016.

[12] P. Martin, Culture, Subculture and Social Organization, in A. Bennett and K. Kahn-Harris (eds) After Subculture: Critical Studies in Contemporary Youth Culture, Palgrave Macmillan, Houndmills, 2004, pp. 21-35.

[13] E.G. Guba, Criteria for assessing the trustworthiness of naturalistic inquiries, Educational Communication and Technology Journal. 29 (1981) 75-91.

[14] Y.S. Lincoln, E.G. Guba, Naturalistic inquiry. Sage, Beverly Hills, 1985.

[15] M.Q. Patton, Qualitative evaluation and research methods, Sage, Thousasnd Oaks, CA, 1990.

[16] M.Q. Patton, Qualitative research and evaluation methods, Third ed., Sage, Thousand Oaks, CA, 2002.

[17] P. Thane, The long history of old age, 2007. 
[18] CASP Checklist for qualitative studies.

http://docs.wixstatic.com/ugd/dded87_25658615020e427da194a325e7773d42.pdf, 2017 (accessed 2

August 2018)

[19] S. Elo, H. Kyngas, The qualitative content analysis process, Journal of Advanced Nursing. 62(1) (2008) 107-115. DOI: 10.1111/j.1365-2648.2007.04569.x

[20] D. Matsumoto, Culture and Psychology, Brooks/Cole, Pacific Grove, CA, 1996.

[21] K. Avruch, Culture \& conflict resolution (Vol. 31), US Institute of Peace Press, 1998.

[22] NVivo qualitative data analysis Software, QSR International Pty Ltd, Melbourne, Australia, 2012.

[23] L. Von Bertalanffy, (1968). General system theory. New York, 1968, p. 40.

[24] S.A. Deetz, Future of the discipline: The challenges, the research, and the social contribution, Annals of the International Communication Association. 17(1) (1994) 565-600.

[25] G. Cipriani, C. Dolciotti, L. Picchi, U. Bonuccelli, (2011). Alzheimer and his disease: a brief history, Neurol Sci. 32 (2011) 275-279. DOI 10.1007/s10072-010-0454-7

[26] E. Poulakou-Rebelakou, G. Kalantzis, C. Tsiamis, D. \& Ploumpidis, (2012). Dementia on the Byzantine throne (ad 330-1453), Geriatrics \& gerontology international. 12(3) (2012) 405-412.

[27] K. Cokayne, Experiencing Old Age in Ancient Rome. Routledge, London, 2003.

[28] D. Laertius, Lives of Eminent Philosophers. R.D. Hicks. Harvard University Press Cambridge, 1972.

[29] N.C. Berchtold, C.W. Cotman, Evolution in the Conceptualization of Dementia and Alzheimer's Disease: Greco-Roman Period to the 1960s, Neurobiology of Aging. 19 (1998) 173-189.

[30] P.J. Rhodes, D.F. Leao, The Laws of Solon: A New Edition with Introduction, Translation and Commentary, I. B. Tauris, 2016.

[31] I. Johnston, Galen: On Diseases and Symptoms, Cambridge University Press, 2006.

[32] A.T. Ban, Dementia: Differential Diagnosis. International Network for the History of Neuropsychopharmacology, (1991) 1-28.

[33] W. Shakespeare, Mr. William Shakespeares Comedies, Histories, \& Tragedies: Published According to the True Originall Copies, Printed by Isaac Iaggard, and Ed[ward] Blount, London, 1623, p. 194. OCLC 606515358.

[34] T. DeBaggio, Losing my mind: An intimate look at life with Alzheimer's. Simon and Schuster, 2002.

[35] Winter Wind" in Something I've Been Meaning to Tell You, 1974, 192-206; in Family Portraits (1978), 57-67; in Literature in Canada (1978), 477-487.

[36] "Pictures of the Ice" in Atlantic Monthly (January 1990), 64-73 (originally created 1990); ;7] in Friend of My Youth, 1990

[37] M. Goldman, Forgotten: Narratives of Age-Related Dementia and Alzheimer's Disease in Canada. McGill-Queen's Press-MQUP, 2017. 
[38] Cicero, Cato Maior de Senectute, Loeb Classical Library, 1923.

DOI:10.4159/DLCL.marcus_tullius_cicero-de_senectute.1923

[39] Alzheimers' Australia, Perceptions of dementia in ethnic communities. Alzheimer's Australia, 2008.

[40] M. Orrell, B. Sahakian, Prevalence of Alzheimer's disease and vascular dementia: association with education, The Rotterdam study, BMJ. 310 (1995) 951-2.

[41] R. Katzman, Views and reviews: education and the prevalence of dementia and Alzheimer's disease, Neurology. 43 (1993) 13-20.

[42] R. Katzman, A neurologist's view of Alzheimer's disease and dementia. International Psychogeriatrics. 16 (2004) 259-273.

[43] Y. Stern, What is cognitive reserve? Theory and research application of the reserve concept, Journal of the International Neuropsychological Society. 8 (2002) 448-460.

[44] M.J. Valenzuela, Brain reserve and the prevention of dementia, Current Opinion in Psychiatry. 21 (2008) 296-302.

[45] D.A. Bennett, J.A. Schneider, J.L. Bienias, D.A. Evans, R.S. Wilson, Mild cognitive impairment is related to Alzheimer disease pathology and cerebral infarctions, Neurology. 64 (2005) $834-41$.

[46] T.D. Koepsell, B.F. Kurland, O. Harel, E.A. Johnson, X.H. Zhou, W.A. Kukull, Education, cognitive function, and severity of neuropathology in Alzheimer disease, Neurology. 70 (2008) 1732 9.

[47] C.M. Roe, C. Xiong, J.P. Miller, N.J. Cairns, J.C. Morris, Interaction of neuritic plaques and education predicts dementia, Alzheimer Dis Assoc Disord. 22 (2008) 188-93.

[48] I. Metzler, A Social History of Disability in the Middle Ages: Cultural Considerations of Physical Impairment, Routledge, 2013.

[49] T.G. Beach, The History of Alzheimer's Disease: Three Debates. The Journal of the history of medicine and allied sciences. 42 (1987) 327-349.

[50] A. Classen, Old age in the Middle Ages and the Renaissance: interdisciplinary approaches to a neglected topic, Walter de Gruyter, 2007.

[51] F. Bacon, B. Montagu, The Works of Francis Bacon (Vol. 1), Parry \& McMillan, 1857.

[52] G. Venzmer, 5000 Years of Medicine, Taplinger Publishing Co, New York, 1968.

[53] C. Gilleard, Aging and old age in medieval society and the transition of modernity, Journal of Aging and Identity. 7(1) (2002) 25-41.

[54] K. Radde-Antweiler, H. Grünenthal, S. Gogolok, (2018). 'Blogging Sometimes Leads to Dementia, Doesn't It?' The Roman Catholic Church in Times of Deep Mediatization, In Communicative Figurations, Palgrave Macmillan, Cham, 2018, pp. 267-286. 
[55] Katholisches. (2015). Accessed: 30 March 2017.

http://www.katholisches.info/2015/09/25/verbloggung-fuehrt-zur-verbloedung-kardinal-marx-ueberkatholische-kritik-am-kurs-der-deutschen-kirche/, 2015 (accessed 13 July 2018).

[56] O. Khan, A. Shah, S.L.Z. Escudero, J. Moriarty, K. Jutlla, V. Goodorally, ... J. Manthorpe, Dementia, Culture and Ethnicity: Issues for All, Jessica Kingsley Publishers 2015.

[57] R. Uwakwe, Knowledge of religious organizations about dementia and their role in care, International journal of geriatric psychiatry. 15(12) (2000) 1152-1153.

[58] F. Mkhonto, I. Hanssen, When people with dementia are perceived as witches. Consequences for patients and nurse education in South Africa, Journal of Clinical Nursing. 30 (2017) 30.

[59] J. La Fontaine, J. Ahuja, N.M. Bradbury, S. Phillips, J.R. Oyebode, Understanding dementia amongst people in minority ethnic and cultural groups, Journal of Advanced Nursing. 60(6) (2007) 605-614.

[60] G.E. Berrios, Dementia during the seventeenth and eighteenth centuries: a conceptual history, Psychological Medicine. 17 (1987) 829-837.

[61] T. Willis, (1684), Practice of Physick. In: Hunter, R.; Macalpaine, I., eds. Three Hundred Years of Psychiatry (1535-1860: A history presented in selected English texts, Hartsdale, Carlisle Publishing, New York, 1982, pp.189-192.

[62] H. Foerstl, R. Howard, A. Burns, R. Levy, (1991). 'The strange mental state of an old man who thought he would be slaughtered'-an early report of dementia with delusion (1785), Journal of the Royal Society of Medicine. 84(7) (1991) 432.

[63] W. Cullen, (1784), First lines in the practice of physic. In: R. Hunter, Macalpine, Three Hundred Years of Psychiatry (1535-1860): A history presented in selected English texts, First ed., Hartsdale, Carlisle Publishing, New York, 1982, pp.473-479.

[64] G.E. Berrios, Alzheimer and the dementias, H. Freeman ed., Royal Society of Medicine Services, 1991, pp. 69-76

[65] P. Higgs, C. Gilleard, Fitness and consumerism in later life, in: E. Tulle, C. Phoenix, (Eds.), Physical Activity and Sport in Later Life: Critical Approaches. Palgrave Macmillan, Basingstoke, 2015.

[66] H. Forstl, Uncommon causes of dementia: an historical account, International Psychogeriatrics. 17 (2005) S3-S15. DOI:10.1017/S1041610205001754

[67] J.E.D. Esquirol, Des passions considérées comme causes, symptômes, et moyens curatifs de l'aliénation mentale, Impremeur de l'Ecole de medicine, Sorbonne, 1805.

[68] G.A. Blumer, The history and use of the term dementia, American Journal of Psychiatry. 63(3) (1907) 337-347.

[69] S.A. Hill, R. Laugharne, (2003). Mania, dementia and melancholia in the 1870s: admissions to a Cornwall asylum, Journal of the Royal Society of Medicine. 96(7) (2003) 361-363.

[70] G.E. Berrios, (1990). Alzheimer's disease: A conceptual history, International journal of geriatric psychiatry. 5 (1990) 355-365. 
[71] E. Kraepelin, Das senile und pra"senile Irresein. eds. Psychiatrie: Ein Lehrbuch für Studierende und Arzte, Johann Ambrosius Barth, Leipzig, 1910, pp. 533-632.

[72] M. Foucault, History of Madness, Khalfa J, editor, translator \& Murphy J, translator, Routledge, New York.

[73] L. Eitner, Gericault: His life and Work, Orbis Publishing, London, 1983.

[74] N. Nixon, (1983-1985), Museum of Modern Art, M.A.E. Boston.

[75] S. Wilks, Clinical notes on atrophy of the brain. J. Ment. Sci. 10 (1864) 10-19.

[76] R.L.K. Virchow, Cellular pathology, Special ed., John Churchill, London, 1859, pp. 204-207.

[77] A. Alzheimer, Uber eine eigenartige Erkrankung der Hirnrinde, Allg. Z. Psychiat, Psych.Gericht. Med. 64 (1907) $146-148$.

[78] O.L. Lopez, E. McDade, M. Riverol, J.T. Becker, Evolution of the diagnostic criteria for degenerative and cognitive disorders, Current opinion in neurology. 24(6) (2011) 532.

[79] G. McKhann, D. Drachman, M. Folstein, R. Katzman, D. Price, E.M. Stadlan, Clinical diagnosis of Alzheimer's disease Report of the NINCDS-ADRDA Work Group* under the auspices of Department of Health and Human Services Task Force on Alzheimer's Disease, Neurology. 34(7) (1984) 939-939.

[80] M.A. Raskind, M.C. Storrie, Organic mental disorders, in: E. Busse, D. Blazer (Eds.), Handbook of geriatric psychiatry, Van Nostrand Reinhold, New York, 1980.

[81] G. Pinner, J. Hillam, T. Branton, A. Ramakrishnan, Faculty of the Psychiatry of Old Age of the Royal College of Psychiatrists, In-patient care for older people within mental health services. https://www.rcpsych.ac.uk/pdf/FR OA 1 forweb.pdf, 2011 (accessed 21 August 2018).

[82] T.S. Szasz, The manufacture of madness: A comparative study of the inquisition and the mental health movement, Syracuse University Press, 1997.

[83] E. Goffman, Asylums: Essays on the social situation of mental patients and other inmates. Routledge, 2017.

[84] J.K. Wing, Comment on institutionalism and schizophrenia 30 years on, British Journal of Psychiatry. 160 (1992) 241-243.

[85] M. Davidge, S. Elias, B. Jayes, K. Wood, J. Yates, Survey of English mental illness hospitals. Prepared for The Mental Health Task Force, Inter-Authority Comparisons and Consultancy, Birmingham, 1993.

[86] Department of Health and Social Security. The Respective Roles of the General Acute and Geriatric Sectors in Care of the Elderly Hospital Patient, DHSS, London, 1981.

[87] T. Kitwood, On being a person. Dementia reconsidered: The person comes first, 1997, pp. 7-19.

[88] M.R. Nolan, J. Brown, S. Davies, J. Nolan, J. Keady, The Senses Framework: improving care for older people through a relationship-centred approach. Getting Research into Practice (GRiP) Report No 2, 2006. 
[89] J. Ballenger, Self, Senility and Alzheimer Disease in Modern America: A History, The Johns Hopkins University Press, Baltimore, MD, 2006.

[90] J. Bowering. Work series on Portraits of dementia sufferers.

[91] S. Sontag, On photography, Penguin, Harmondsworth, Middlesex, 1979.

[92] C. Thomas, C. Milligan, How can and should UK society adjust to dementia?. Joseph Rowntree Viewpoint, 2015.

[93] J. Adamson, Awareness and understanding of dementia in African/Caribbean and South Asian families, Health \& social care in the community. 9(6) (2001) 391-396.

[94] L. Hinton, J.N. Tran, C. Tran, D. Hinton, Religious and spiritual dimensions of the Vietnamese dementia caregiving experience. Hallym international journal of aging HIJA. 10(2) (2008) 139.

[95] K.F. Jett, Mind-loss in the African American community: Dementia as a normal part of aging, Journal of Aging Studies. 20(1) (2006) 1-10.

[96] P. Kontos, W. Martin, Embodiment and dementia: Exploring critical narratives of selfhood, surveillance, and dementia care, Dementia. 12(3) (2013) 288-302.

[97] H. Sweeting, M. Gilhooly, Dementia and the phenomenon of social death. Sociology of Health \& Illness. 19(1) (1997) 93-117.

[98] R. Bar-On, Emotional intelligence and self-actualization. Emotional intelligence in everyday life: A scientific inquiry, 2001, 82-97.

[99] W. Hulko, From 'not a big deal'to 'hellish': experiences of older people with dementia, Journal of Aging studies. 23(3) (2009) 131-144.

[100] H. Aldridge, P. Fisher, K. Laidlaw, Experiences of shame for people with dementia: An Interpretative Phenomenological Analysis, Dementia. (2017), 1471301217732430.

[101] K. Swaffer, Dementia: stigma, language, and dementia-friendly. Dementia, (2014) 709-716.

[102] E. Sørensen, J. Torfing, Network politics, political capital, and democracy, International journal of public administration. 26(6) (2003) 609-634.

[103] R.D. Putnam, Democracies in flux: The evolution of social capital in contemporary society, Oxford University Press, USA, 2002.

[104] D. Moher, A. Liberati, J. Tetzlaff, D.G. Altman, Preferred Reporting Items for Systematic Reviews and Meta-Analyses: The PRISMA Statement, British Medical Journal. 339 (2009) 25-35.

[105] K. Heese, Ageing, dementia and society-an epistemological perspective. Springer Plus, 4(1) (2015) 135.

[106] Social Care Institute for excellence, Co-production in social care: What it is and how to do it. http://www.scie.org.uk/publications/guides/guide51/what-is-coproduction/defining-coproduction.asp, 2013 (accessed 24 June 2018). 
